\title{
The Instrument of Teaching Metacognition in Reading Classrooms: The ITMR
}

\section{Nesrin Ozturk (D) 1,*}

${ }^{1}$ Izmir Democracy University, Department of Educational Sciences, 35140, Izmir, Turkey

\begin{abstract}
ARTICLE HISTORY
Received: March 19, 2020

Revised: July 3, 2020

Accepted: August 08, 2020

KEYWORDS

Metacognition,

Instruction,

Reading,

Assessment,

Thinking

Abstract: Limited influence of metacognition research in mainstream classrooms may stem from a lack of comprehensive pedagogy and/or inconsistent criteria assessing metacognition instruction. For this problem, an instrument designed for metacognition instruction in reading classes was examined. After a systematic and analytic review of broad literature, scale validation procedures were followed. Items that represent observable and measurable teacher-behavior promoting students' metacognition were generated. Next, QUAID examination, expert-, cognitive-, and focus-group interviews were conducted. Data collected from reading teachers via a computer-assisted survey method were analyzed by exploratory factor analysis, Welch's, and Spearman's tests. Findings confirmed that the ITMR had a unidimensional model accounting for $60 \%$ of metacognition instruction $(\alpha .97)$. There were no mean differences in metacognition instruction at any elementary grades. The items on the ITMR were also strongly and positively correlated. Thereby, the ITMR can be used to assist and identify classroom metacognition instruction in reading classrooms.
\end{abstract}

\section{INTRODUCTION}

Meaning making in reading pertains to actions and interactions of perceptual processes, cognitive skills, and metacognition (Book, Duffy, Roehler, Meloth, \& Vavrus, 1985; Doğanay Bilgi \& Özmen, 2014; Myers \& Paris, 1978). Readers use cognitive strategies for task demands (Doğanay Bilgi \& Özmen, 2014; Garner, 1987; Gourgey, 2001) and simultaneously, they employ metacognition for the effectiveness of cognitive resources (Gourgey, 1998, 2001).

Research demonstrated that metacognition can be successfully taught (Ozturk, 2015) and such trainings can help limited and/ or no metacognitive adequacy (Anastasiou \& Griva, 2009; Van Keer \& Vanderlinde, 2010; Veenman, Van Hout-Wolters, \& Afflerbach, 2006). Following metacognition trainings, research found that individuals' vocabulary, reading awareness, skills, comprehension, and performances improve (e.g. Boulware-Gooden, Carreker, Thornhill, \& Joshi, 2007; Cross \& Paris, 1988; Curwen, Miller, White-Smith, \& Calfee, 2010; MuñizSwicegood, 1994; Veenman et al., 2006).

CONTACT: Nesrin Ozturk $\bigotimes$ ozturknesrin@gmail.com @ Izmir Democracy University, College of Education, Department of Educational Sciences, 35140, Izmir, Turkey 


\subsection{Problem and Purpose of the Research}

Until the early 2000s, metacognition instruction research confirmed beneficiary impacts of various instructional programs, approaches, techniques, and methods. However, as Duffy (2002) emphasized, 'research focus must be on thoughtfully adaptive teaching` (p.36). That is, instead of searching for 'foolproof" (Duffy, 2002, p.36) practices such as K-W-L, direct explanation, and/or modeling, research must focus on teachers who would possess and improve a mindset of being metacognitive. In alignment with Duffy's arguments, Van Keer and Vanderlinde (2010) and recently Baker (2017) highlighted that albeit research in this field, the degree to which mainstream classroom students demonstrate and practice metacognition is not similar to the ones in research. This discrepancy may stem from either an unsatisfied need for the directives to teach metacognition in classrooms (Kerndl \& Aberšek, 2012; Veenman et al., 2006) or teachers' instruction that lacks pedagogies of metacognition (e.g. Curwen et al., 2010; Kerndl \& Aberšek, 2012; Perry, Hutchinson, \& Thauberger, 2008; Thomas \& Barksdale-ladd, 2000). Although verbalized slightly different, such a discrepancy put forward the need to lay out a practical understanding of metacognition instruction.

The argument that teachers' instruction lacks practices for metacognition might be strong while there are limitations in extant research assessing metacognition instruction in mainstream classrooms. Such research has not exclusively identified the factors that represent metacognition instruction and has not consistently captured them, yet. That is, research in this realm has operated different indicators for metacognition instruction and has not paid enough attention to the lack of a research-based standardized measure of metacognition instruction as presented in the following section. For these reasons, observable and measureable standardized criteria for metacognition instruction should be developed and then, examined before labelling classroom instruction. Regarding substantial domain-specific nature of metacognition (Papleontiou-louca, 2003; Schraw, 2001; Tishman \& Perkins, 1997; Veenman, 2016; Zimmerman, 2000), this study aims to examine the psychometric characteristics of a metacognition instruction instrument for reading classrooms at elementary school level.

\subsection{Literature Review}

Metacognition pertains to thinking about thinking and it involves metacognitive knowledge, metacognitive strategies, and metacognitive experiences (Flavell, 1979). Metacognitive readers have knowledge about themselves, genres, topics, task demands, and strategies. They can also employ metacognitive strategies; i.e. planning, monitoring, regulating, and evaluating (Bransford, Brown, \& Cocking, 2000; Pintrich, Wolters, \& Baxter, 2000; Pintrich, 2002) for various task demands. Metacognitive experiences, on the other hand, occur when readers actively engage in higher-order thinking (i.e. strategic reading). That is, strategic reading occurs when individuals think about the text and strategies purposefully, manage task demands and goals actively, and building comprehension, successfully.

To develop the instrument of teaching metacognition in reading classrooms (the ITMR), I studied a broad set of literature (around $\mathrm{N}=110$ ) including books, research, and conceptual papers on metacognition $(\mathrm{N}=96)$, social learning theories $(\mathrm{N}=5)$, and gradual release of responsibility framework $(\mathrm{N}=2)$. For the limitations of space and focus of the paper, I will shortly declare the categories by which a systematical and analytical review was done in the following.

Initially, I identified and determined how to develop and foster students' metacognition in reading classrooms. For this task, I reviewed (a) metacognition theory, (b) characteristics of metacognitive readers, (c) metacognition assessment of students' competency, (d) meditations on metacognition instruction, (e) empirical research on metacognition instruction, and (f) supplementary instructional practices for metacognition. After reviewing the previous section, 
I recognized the need to study social learning theories including; (g) social learning theory (Bandura, 1986, 1971), (h) self-regulated learning (Zimmerman, 2000, 2002), and (i) social constructivism (Vygotsky, 1978). Then, as the ultimate goal is to educate self-directed learners, I reviewed (j) gradual release of responsibility framework (Fisher \& Frey, 2013; Pearson \& Gallagher, 1983). Finally, I also reviewed (k) research studies assessing teachers' metacognition instruction $(\mathrm{N}=13)$ to polish the criteria on the ITMR.

By the insights developed reviwing the previous section, I defined a pedagogy of metacognition. A pedagogy of metacognition (PMR) pertains to the instruction for which teachers employ their metacognition, effective instructional practices for teaching metacognition, and metacognition assessment practices by the principles of social learning theories, purposefully. The purpose of a PMR pertains to developing and fostering students' metacognitive autonomy via a gradual release of responsibility trajectory. I also concluded that generic metacognition instruction can be implemented by seven main components. These include (a) fostering students' metacognitive knowledge, (b) scaffolding students' strategic reading, (c) encouraging students' independence with strategic reading, (d) assessing metacognition, (e) adopting goal directedness, (f) integrating language of thinking, and (g) prolonging metacognition instruction (Ozturk, 2017b).

Development of a PMR was compulsory to harmonize the previous theoretical foundations so as to transfer meatcognition instruction into mainstream classrooms. Specifcially, a PMR helped develop behavioral indicators of metacognition instruction. However, such a pedagogy needs cross-checking with the criteria presented by the extant research assessing pedagogical practices of metacognition. Therefore, items on the ITMR can be confirmed for further investigation. In the following, available research that scrutinized specifications with teaching metacognition will be presented.

\subsubsection{Literature on metacognition instruction assessment}

The purpose of this section was to detect available measurement criteria of metacognition instruction in the literature. By these criteria, the ITMR items developed following a PMR can be confirmed and/or improved, if at all. In this section, available literature assessing metacognition instruction was categorized into two sets; standardized instruments $(\mathrm{N}=1)$ and qualitative research $(\mathrm{N}=10)$.

\subsubsection{Standardized measurement instruments}

Following an extensive literature review, Wilson and Bai (2010) found that there were no standardized measurement instruments assessing teachers' metacognitive knowledge and pedagogies of metacognition. Therefore, they recruited 105 graduate students who were K-12 teachers majoring in different areas to develop an instrument measuring teachers' understandings, pedagogical knowledge, and beliefs about metacognition. Their confirmatory factor analysis produced a survey of 20 items that can be rated on a 4 point Likert-scale. They found that the items loaded on 4 factors $(p>.05)$ with at least $\alpha>.7$ for each. This model explains $61 \%$ of the variance in teachers' knowledge and pedagogies of metacognition.

This measurement is a domain general instrument and it covered some instructional practices basically divided into two sets; (a) evaluating students' metacognitive processing and (b) teaching students to use metacognitive thinking strategies. The first set included

- teachers' evaluating students' planning the logistics,

- describing the steps and explaining the rationale of each step for a task-completion,

- being aware of their reasoning in completing a task, and

- describing their actions and learning. 
The second set of items pertained to teaching students metacognitive thinking strategies by

- providing students with problem-solving activities,

- increasing students' metacognitive knowledge about thinking strategies in relation to specific objectives,

- having students share their thinking,

- facilitating students' discussions on problem solving,

- modelling students thinking processes,

- having students generate questions regarding the content, and

- having students explain the procedures and processes for their answers or taskcompletion.

Wilson and Bai's (2010) instrument was the first standardized measurement assessing teachers' knowledge and pedagogical understandings of metacognition; however, it posed some limitations. First of all, this survey does not assess what teachers do but what they know (p.286). Moreover, the items are rated on an agreement-scale; therefore, the survey can identify teachers' beliefs about pedagogical understandings of metacognition. Also, this instrument was not specifically designed for reading classrooms. Because behavioral indicators are domaingeneral, they might be vague for some reading teachers. The survey also includes some hypothetical and/or very specific items (e.g. creating a roller coaster, creating a Venn diagram, and completing an essay on Sherman's March on Atlanta etc.); these may jeopardize the validity of the instrument. Still, although this measure has some limitations and domain-general characteristics, it is used frequently since then.

\subsubsection{Qualitative studies}

The earliest study in qualitative realm was conducted by Kurtz, Schneider, Carr, Borkowski, and Rellinger (1990). In their study, metacognition instruction was assessed by various questions. These questions had participant-teachers (a) make some instructional decisions after reading different scenrios $(\mathrm{N}=3)$, (b) react to the scenerios as True or False $(\mathrm{N}=4)$, (c) determine instructional techniques or methods $(\mathrm{N}=2)$, and rate the statements on a 5-point frequency scale $(\mathrm{N}=2)$. However, when these items are examined closely, only 3 of them can identify metacognition instruction. These items include teaching different learning strategies appropriate to different tasks, giving specific instruction for learning strategies, and informing students about benefits of those strategies.

Duffy (1993) also studied teachers' pedagogies of metacognition. Examining lesson-transcripts, interviews with students, and class-observation, Duffy utilized the following criteria for identifying metacognition instruction; teachers' explaining the rationale for learning strategies, modelling strategic reasoning, as well as scaffolding and providing feedback for students' thinking.

Moreover, Zohar (1999) examined teachers' knowledge and practices of metacognition instruction. However, they did not provide any categories or codes for the analysis. Therefore, I coded their findings to identify potential criteria representing metacognition instruction. The findings mostly focused on explicit teaching of thinking skills, holding metacognitive discussions, and modeling thinking as well as reasoning during problem solving.

Thomas and Barksdale-ladd (2000) also did a study with pre-service teachers. They analyzed student-teachers' reflective journals of tutoring to young readers for their instructional approaches. To capture metacognition instruction, they used the following criteria; demonstrating and/or modeling a reading process aloud, children's reading and thinking aloud, and children's doing reflection on what they read. 
Bolhuis and Voeten (2001) examined teachers' practices of metacognition instruction. At secondary education level, they did an observation study. To analyze the data, they obtained the following criteria; teachers' explaining learning strategies, questioning students' learning activities and the importance of subject-matter, students' engagement in learning, problem solving and learning strategies, teachers' giving feedback, teachers' coaching students to monitor and evaluate their learning as well as to manage task difficulties, and teachers' informing students about the learning goals and their relevance to out-of-school contexts.

In another observation study, Fisher (2002) studied teachers' instructional practices for metacognition. In this study, Fisher set teachers' modeling thinking skills and demonstrating metacognitive regulation (i.e. showing how to achieve a goal) as the criteria to capture metacognition instruction.

Perry and colleagues (2008) also studied metacognition instruction. Their criterion included teachers' providing students with opportunities to make choices, control challenge, and engage in self-assessment, modeling, using explicit language, and scaffolding learning.

Furthermore, Curwen and colleagues (2010) studied metacognition instruction through classroom-observations and interviews with teachers during a professional development period. They analyzed teachers' explicit comprehension instruction, students' practice and use of comprehension strategies, students' reflections on new ways of thinking, as well as increased student responsibility and ownership of learning. Teachers were also asked to implement some instructional techniques such as activating background knowledge, thinking aloud, using graphic organizers, analyzing text structure, reflecting on writing prompts and content ideas, as well as synthesizing knowledge.

Moreover, Kerndl and Aberšek (2012) examined teachers' competence with metacognition instruction. They did not present data analysis codes, explicitly. Therefore, I coded their findings and found that they mostly focused on teachers' helping students improve metacognitive knowledge and thinking about their cognitive engagements. Also, helping students monitor and evaluate cognitive processes as well as products was paid attention.

Finally, I also examined pre-service teachers' pedagogies of metacognition (Ozturk, 2016). In this study, I used teachers' modeling and/or thinking aloud strategic reading, informedstrategies teaching, scaffolding students' strategic reading, and having students do selfassessment.

Extant studies are crucial to help identify and confirm behavioral indicators of metacognition instruction; however, they pose some limitations. In almost none of these studies, metacognition instruction was sufficiently defined. Moreover, teachers' pedagogies of metacognition were examined divergently and inconsistently. Without a pedagogical framework, each and every study examined various behavioral indicators of metacognition instruction. Those indicators were not defined and contextualized sufficiently, either. Therefore, such methodologies might not help classroom teachers inform and adjust their instruction for metacognition practices, deliberately.

\subsubsection{Short summary of literature on metacognition instruction assessment}

This section aimed to identify extant criteria for metacognition instruction. I realized that while research utilized divergent criteria for metacognition insturtcion, it did not define and/or conceptualize metacognition instruction and its criteria, sufficiently. Still, extent metacognition instruction criteria mostly either aligned with the gradual release of responsibility framework or reflected fundamental principles of social learning theories.

Extant metacognition instruction assessment practices specifically utilized the following; teachers' increasing students' metacognitive knowledge of cognitive strategies and thinking 
skills, using an explicit language for informed-strategies-teaching, modeling a cognitive endeavor, thinking and/or reasoning during it, demonstrating a reading process and metacognitive regulation, holding metacognitive discussions with students, informing students about learning goals, having students think-aloud their cognitive endeavors and reflect on them, having students practice strategies and thinking skills, having students engage in problem solving, using strategies, controlling challenge and managing task difficulties, coaching students or providing students with scaffolding during cognitive endeavors and feedback for these activities, initiating students' metacognitive discussions, having students do selfassessment, assessing students' metacognitive practices, and having students develop an ownership of learning.

\section{METHOD}

\subsection{Research Design}

This study represents a structured-survey research model. The survey was delivered online for (a) people's tendency to give more honest answers (Sue \& Ritter, 2012), (b) being less likely to over- and/or over- report behaviors when responding to the statements on one's own (Bradburn, Sudman, \& Wansink, 2004), and (c) limiting any aid or influence from the researcher as suggested by (Andres, 2012).

\subsection{Validation of the ITMR}

To Schwab (1980), scale validation can be complete in three steps; (1) item generation, (2) scale development, and (3) psychometric examination. In the following section, the first two stages will be described; however, the last stage pertains to data analysis. Therefore, it will constitute the results section of this paper.

\subsubsection{Item generation}

Items for the ITMR were generated after a PMR was developed with a focus on content validity. For this task, teacher-behaviors (i.e. modelling, explaining, and explicitly teaching strategies, teachers' cooperation with students, initiating students' metacognitive discussions, assessing students' metacognitive acts, students' self-assessment, and students' independence with metacognitive endeavors) fostering students' metacognitive behaviors (i.e. planning by task and text evaluation, strategy selection, monitoring, and performance evaluation) were described. Indeed, these behavioral indicators represent the theoretical foundations for what teachers can do to develop metacognitive competencies in students. Then, these behaviors were crosschecked against the previous researches' categories and/or codes of metacognition instruction assessment practices. Following these steps, the initial set of survey items $(\mathrm{N}=76)$ was created.

This survey asked respondents to reflect on and rate their firsthand experiences of teaching metacognition in reading classes. All items were positively worded to control the validity of responses and systematic error (Hinkin, 1995). All statements were accompanied with a bipolar rating scale ranging from (0) not like me to (100) exactly like me. Following these procedures, all items were examined on QUAID (question understanding) to identify unfamiliar words (e.g. explicitly, monitoring, and feedback) that might hinder comprehension.

\subsubsection{Scale development}

At this stage, the initial items were examined whether and how well they confirm the expectations about the structure and content of the instrument as Hinkin (1995) suggested. For this task, I followed Fowler's (1995) guideline and consulted experts, interviewed with colleagues in the field, and held a discussion session with in-service teachers.

First of all, I held meetings with experts. There were 3 experts whom I consulted for content and construct validity of the survey items. They are distinguished scholars who taught at a Mid- 
Atlantic public research university in the USA. Each expert had at least 25 years of teaching and research experience in metacognition, strategic processing, strategy teaching, and assessments. Experts were consulted twice for their validity-judgements.

On the first round of expert judgments, I took the initial set and asked whether the survey covers the phenomenon appropriately and reflects its characterization in the domain of reading. Then, I asked them both to respond to the statements and think how potential respondents would comprehend the statements. They were specifically asked whether and what kind of problems the respondents might experience while filling out the survey. Wording of the items were revised based on their feedback. Then, items were presented to cognitive and focus group interview participants.

Following the first round of expert-judgmenet meetings, I held cognitive interviews where colleagues described their thoughts aloud (Fowler, 1995). By cognitive interviews, problems in comprehending the statements, response selection, and appropriateness and relevance of the content can be determined (Fowler, 2009). For these benefits, I held four think-loud interviews with the colleagues ( 3 females and 1 male). They were familiar with metacognition theory and reading education in the USA. They all held a reading specialist certificate. Their teaching experience ranged from 8 to 13 years. Each interview took around 40 minutes. During each interview, on average 20 statements were studied. The interviewees were specifically asked to paraphrase their understanding of the statements, define the terms, express any confusion or uncertainties while rating the statements, and think about the classroom implementations of the instructional practices. Moreover, participants were also asked how they arrived at choosing a number and how their answers would differ from mainstream classroom teachers. Cognitive interview participants were mostly concerned with the conventions of language. Based on their feedback, I did grammatical revisions. I also took some notes for item-reduction because there were numerous items that sounded very similar.

Along with the cognitive interviews, I also held a focus-group discussion session. Focus group interviews are systematic discussions about the construct under study to identify threads to standardization and to neutralize the complexities that would cause ambiguity (Fowler, 1995). For this study, a relatively homogenous focus-group of eight in-service reading teachers was recruited. At the time of study, they pursued a master's degree in reading education at a MidAtlantic public research university. Focus-group participants either taught at elementary $(\mathrm{N}=5)$ or middle $(\mathrm{N}=3)$ school level. They also had two to eight years of teaching experience. The focus group discussion was conducted during a graduate class. Participants were distributed the initial ITMR and given 30 minutes to study the statements on their own. They were asked to respond to the statements and think whether they would need assistance for clarification. Then, focus-group participants and I discussed the statements for another 30 minutes. I checked QUAID feedback with them and participants reported no problems interpreting the items that included "feedback, explicitly, and monitoring". Therefore, I kept these items for the last version of the ITMR. I also checked the items with focus group for reduction. Following the discussion session, the items to be reduced were identified.

After cognitive interviews and focus-group discussion, I consulted two experts, again. Following the previous procedures, the survey was narrowed down to 40 items representing an intersection of metacognition instruction and students' metacognitive behaviors. Then, these items were transferred to an electronic platform (Qualtrics). Before the survey was delivered to the participants, a few procedures were completed to control any possible factors (i.e. timing, font, and font size) that might impact participants' experiences with the ITMR. The following figure (i.e. Figure 1) presents procedures for the development of the ITMR 


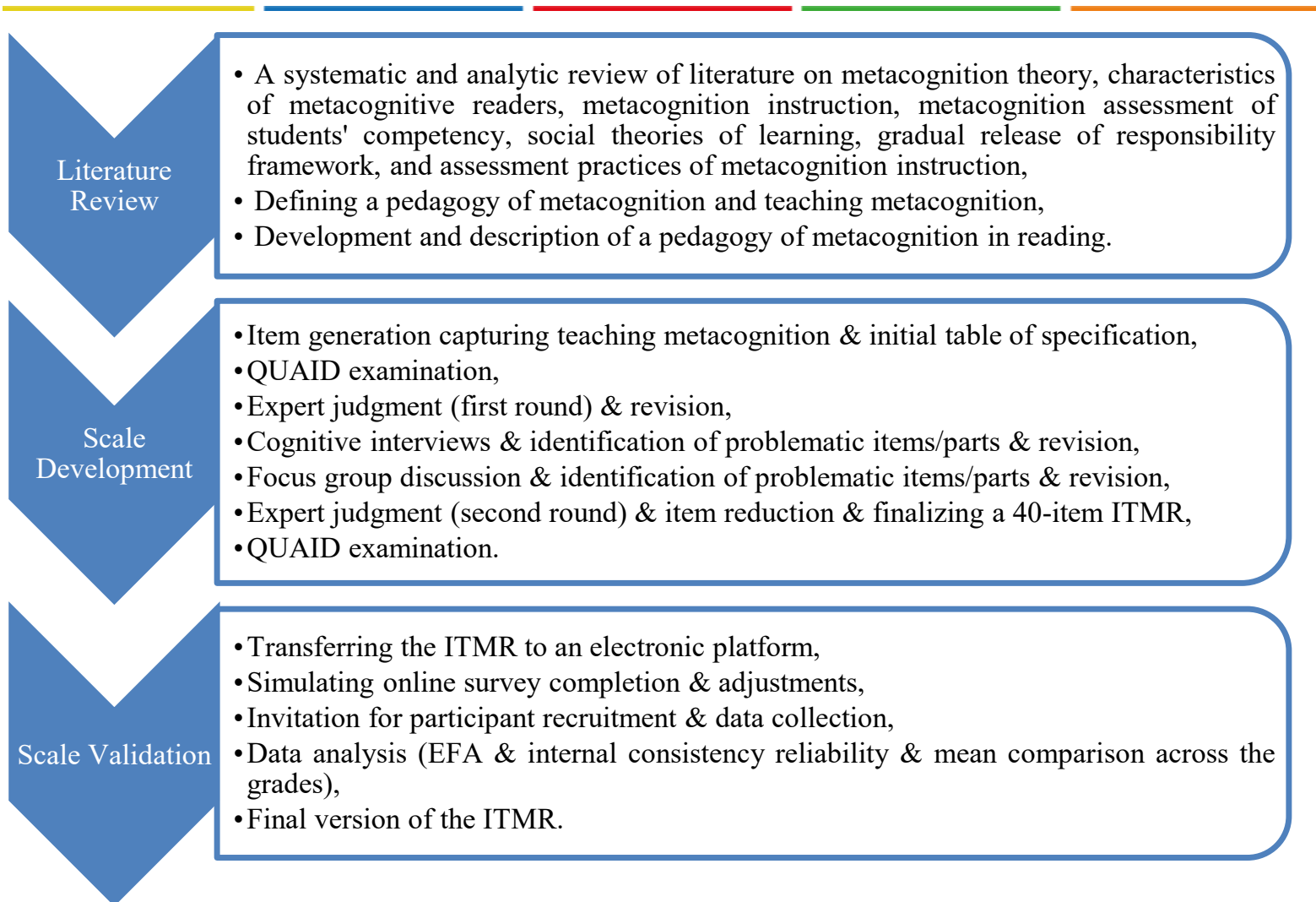

Figure 1. Scale validation procedures

\subsection{Data Collection Procedures}

Before collecting the data, I made sure that every participant would respond to the same statements, in the same order, and on the same platform to ensure standardization. Following this, I posted a research-invitation to my academic and social networks (e.g. Facebook, LinkedIn, Twitter, ILA, and LRA) to recruit respondents. The invitation included details about the research; purpose, survey completion time, scale type, and participation criteria. To control social desirability, as Bradburn et al. (2004), Fowler, (2009, 1995), Netemeyer, Bearde, and Sharma (2003), as well as Sue and Ritter (2012) suggested, I also assured anonymity and confidentiality of the data. The survey link was active for a month.

\subsection{Participants}

Target population of this study was specified regarding empirical research practices and theoretical insights. The earliest grade was determined as the first grade regarding Veenman's (2016) and Veenman et al.'s (2006) arguments of that from the age of 8, children can show evidence for metacognitive strategies, efficiently. Considering substantial domain specific manifestations of metacognition, the 5th grade was determined as the upper limit. In addition, regarding Andres's (2012) criteria of grouping unit, geographic boundaries, and time; the sample of this study was narrowed to grade 1 to grade 5 teachers who teach reading in the United States of America during the 2016-2017 academic year. I employed a semi nonprobability sampling technique to recruit respondents via online modules because of my limited access to target population. At the end of a month, only 211 of 314 voluntary respondents either satisfied recruitment criteria or provided complete data.

\subsubsection{Demographics of the sample}

Demographics report respondents' gender, teaching experience, grade, and education level. 211 elementary teachers were dominantly represented by females; there were only nine $(4.3 \%)$ 
males. There were $71(33.6 \%)$ teachers with a bachelor's degree and $140(66.3 \%)$ held a graduate degree. 137 (64.9\%) had a master's and three had a doctoral degree. Respondents taught in various states of the USA; 41 states and D.C. Of these teachers, 34 taught 1 st and 5th graders, 35 taught 4 th graders, 48 taught 2 nd graders, and the rest 60 taught 3 rd graders. Teaching experience ranged between a minimum of 1 and a maximum of 40 (years) with a $M=14.66, S D=8.85$.

\subsubsection{Determination of the sample size}

To determine the sample size, I considered recommendations in the literature. To develop a new scale DeVellis (2012), Hinkin (1995), and Nunnally (1978) suggested recruitment of 200, 150, and 300 participants, respectively. Moreover, Bartlett, Kotrlik, and Higgins (2001) emphasized that the ratio of observations to independent variable should not fall below a minimum of 5 .

Following data collection, I examined the adequacy of sampling. For this purpose, I conducted an analysis of component saturation regarding de Winter, Dodou, and Wieringa's (2009) and Guadagnoli and Velicer's (1988) recommendations. As de Winter et al., (2009) showed evidence, when the data are well-conditioned with high loadings, small number of factors, and high number of variables; factor analysis can yield reliable results for a sample size. By these criteria and exploratory factor analyses' results, the data set was confirmed adequate.

\subsubsection{Post-stratification}

Before examining the psychometric properties of the ITMR, I approximated sample's data to the population. For this purpose, I used the most recent data (2011-2012) at the time of this study (Rahman, Fox, Ikoma, \& Gray, 2017). Because the sample might diverge from its population, the data were also post-stratified by teachers' education level and Goldring, Gray, and Bitterman's (2013) measures. After this, two iterations of exploratory factor analysis (EFA) were run (original data and weighted data). These two solutions identified the same items constituting the ITMR at elementary school level.

\subsection{Data Analysis Procedures}

Psychometric examination was the last stage of the scale validation in this study. The data were analyzed for (1) the variation in the items so that it could possibly be explained by fewer factors, (2) possible mean differences in metacognition instruction across elementary school grades, and (3) possible correlations among the instructional practices on the ITMR.

\subsubsection{Determination of data's suitability to factor analysis}

I examined Kaiser-Meyer-Olkin (KMO), Bartlett's test of Sphericity, and correlation matrix to verify data's suitability to the EFA. I found the factorability adequacy of sampling was satisfactory; the KMO test indicated a value of .953, Bartlett's test of sphericity was significant $\left(\chi^{2}=7105.197, d f=780, p<.05\right)$, and all item correlations were significant at $p<.05$.

\subsubsection{Determination of the factor numbers}

After confirming data's factorability, I conducted a principal component analysis (PCA) to determine the number of the initial factors. For this purpose, I (a) used Eigenvalues (retained factors with eigenvalues $\geq 1$ ), (b) examined the scree test, and (c) run Monte Carlo PCA for parallel analysis, and (d) considered that a factor is to explain at least $5 \%$ of the variance (DeVellis, 2012; Netemeyer et al., 2003). By these criteria, I run a factor analysis. Although I could identify instructional practices for a PMR and although metacognition theory proposes 3 main categories and 3 subsets for metacognitive knowledge and regulation, respectively, I restrained from hypothesizing about the structure of the instruction in mainstream classrooms. That is, it may not be realistic to separate instructional practices from one another in classrooms 
and these practices might foster different metacognitive components and/or characteristics in different students. Therefore, I run an exploratory factor analysis.

\subsubsection{Factor analysis}

Following the previous steps of factor extraction, I conducted a principal axis factoring with varimax rotation and determined the most salient items. For this task, I examined the communalities, rotated factor loadings, and considered content validity of the scale. By the criteria that Netemeyer et al. (2003) proposed, I deleted items which load insignificantly $(<.45)$ and items with extremely high loadings $(>.90)$ from the final ITMR.

Moreover, I regarded content validity to retain items. I examined items that contained relevant information for classroom practices of metacognition instruction for its salience. Therefore, I deleted some items (e.g. I have students assess their own text evaluations (e.g. topic, structure, or genre) before reading) although they had communalities $\geq .44$. By these procedures, the final ITMR included 24 items and they will be presented in the results section of this study.

\subsubsection{Internal consistency reliability}

I examined the scale's reliability by internal consistency reliability. The ITMR produced an $\alpha .97$

\subsubsection{Comparison of mean differences}

The items were analyzed in groups to identify any grade-level differences. Considering the data's characteristics, I run a non-parametric test (Welch's test and Games-Howell post hoc analysis) to examine the mean differences in metacognition instruction practices across elementary school grades.

\section{RESULT}

\subsection{The ITMR at Elementary School Level}

A principal axis factoring with varimax rotation generated a unidimensional (single factor) model that accounted for $60 \%$ of the total variance in metacognition instruction. Item loadings ranged from .865 to .666 . The internal consistency reliability was calculated as $\alpha=.97$. The ITMR had 24 items (Table 1).

Table 1. The ITMR at elementary school level

\begin{tabular}{ll}
\hline Items & $\begin{array}{l}\text { Factor } \\
\text { Loadings }\end{array}$ \\
\hline I have students demonstrate their independent text evaluations (e.g. topic, structure, or & .865 \\
genre) before reading. & .848 \\
I have students demonstrate their independent task evaluations. & .835 \\
I have students assess their own task evaluation. & .820 \\
I have students discuss their text evaluations (e.g. topic, structure, or genre) before & \\
reading. & .818 \\
I explicitly teach students how to evaluate their task performance. & .813 \\
I explain why evaluating task performance is important. & .801 \\
I have students assess their own task performance. & .801 \\
I explicitly teach students how to evaluate the task they are given. & .799 \\
I have students discuss their strategies selection for the reading task & .798 \\
I have students assess their own monitoring text understanding during reading. & .794 \\
I have students demonstrate their independent task performance evaluations. & \\
\hline
\end{tabular}


I explain why task evaluation is important for task performance.

.788

I explicitly teach students how to evaluate the text (e.g. topic, structure, or genre) before $\quad .781$ reading.

I provide feedback on students' strategy selections for the reading task.

I model how I evaluate my task performance.

I help students while they are evaluating the text (e.g. topic, structure, or genre) before

reading.

I provide feedback on students' monitoring text understanding during reading.

I provide feedback on students' task performance evaluations.

.749

I have students assess their own strategy selection for the reading task.

.746

I have students discuss their task evaluations.

I help students while they are selecting appropriate reading strategies for the reading task.

I provide feedback on students' text evaluations (e.g. topic, structure, or genre) before reading.

I help students while they are evaluating the task they are given.

I have students demonstrate their independent monitoring text understanding during

.666 reading.

\subsection{Metacognition Instruction across Elementary School Grades}

By a Welch's test, it was confirmed that there were no statistically significant mean differences representing metacognition instruction across any elementary grades, Fmodel $(4,88)=1.15$ $p=.34 ;$ Fexplain $(4,87.88)=.2 .25, \quad p=.07 ; \quad$ Fexplicitlyteach $(4,89.6)=942, \quad p=.444$; Fscaffoldteach $(4,90.5)=.702, p=.59 ;$ Fscaffolpeer $(4,90.36)=1.56, p=.19 ;$ Fassessteach (4, $89.6)=1.70, p=.156$; Fassesself $(4,89.97)=.835, p=.506$, and Findependet $(4,90.7)=1.14$, $p=.339$.

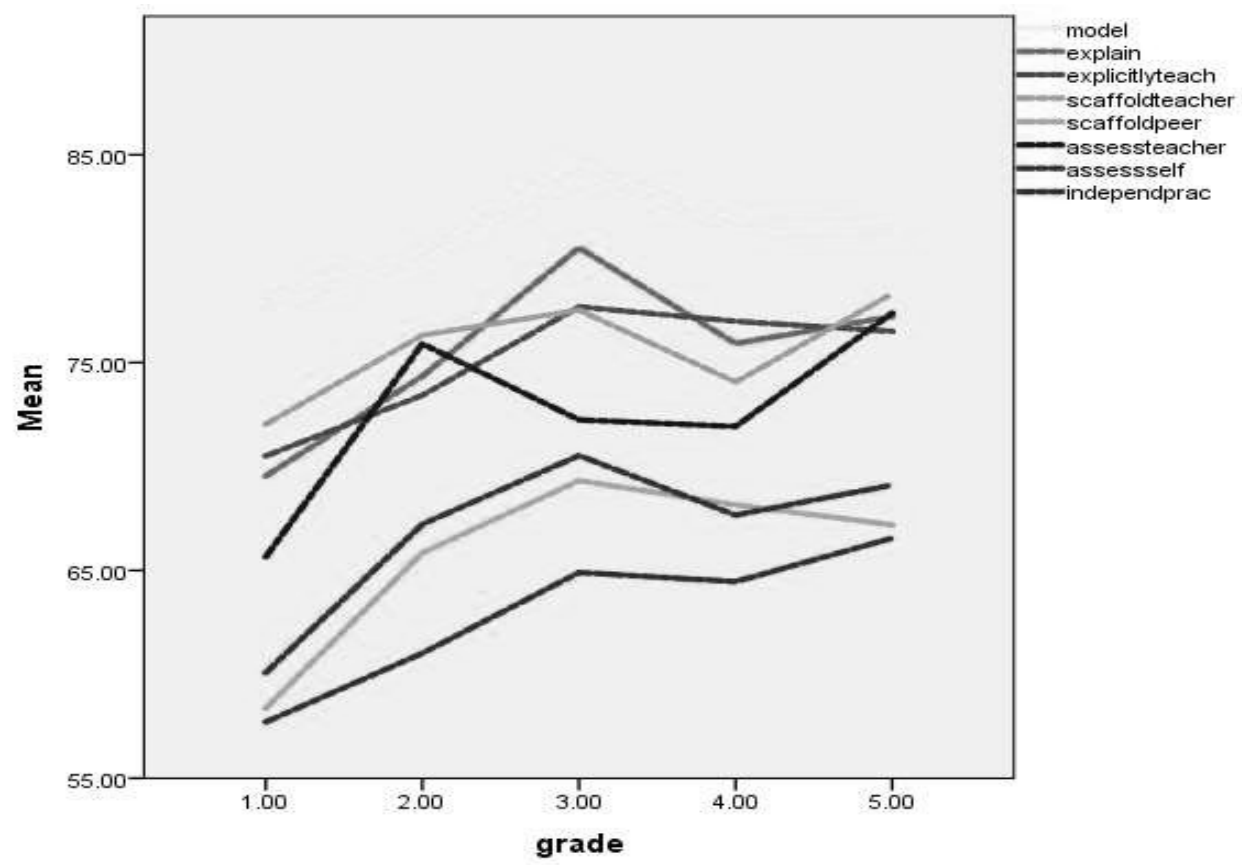

Figure 2. Metacognition instruction across elementary grades 


\subsection{Correlations among ITMR's Items}

A series of Spearman's correlation analyses were conducted to examine the relations among the items representing instructional practices on the ITMR. A two-tailed test of significance indicated that all correlation coefficients were statistically significant, strong, and positive, $r_{s}$ $(211)=+.68, p<.01$.

\section{DISCUSSION and CONCLUSION}

This study was conducted on the premise of metacognition research's utility for classroom metacognition instruction. Although metacognition research has a long history, the discrepancy between mainstream and research classroom realities regarding students' metacognition competency and proficiency has not been eliminated (Baker, 2017; Carroll, 2008; Curwen et al., 2010; Van Keer \& Vanderlinde, 2010). Congruently, teachers' need for practical tools to teach metacognition in classrooms is still not satisfied (Kerndl \& Aberšek, 2012). While such problems and needs are still valid, research keeps evaluating classroom metacognition instruction via inconsistent and sometimes, vague criteria. Addressing these urgencies, this study was the first initiative of identifying classroom metacognition instruction in reading classrooms by an instrument; the ITMR. Statistical analyses provided evidence for the ITMR's internal consistency ( $\alpha .97$ ). The ITMR explained $60 \%$ of the total variance in metacognition instruction by a single factor constituting 24 items. The ITMR, currently, may be the only measure of metacognition instruction in the field of reading.

Furthermore, the ITMR can be used across elementary grades. Statistical examination provided evidence for that instructional practices did not show any significant variance at least any two elementary school grades; on the contrary, a similar pattern of metacognition instruction can be observed across all elementary grades. While instructional practices such as modelling, explaining, explicitly teaching, and teacher's scaffolding strategic reading were frequently implemented in mainstream classrooms, students' doing self-assessment was the least frequently implemented practice across all elementary grades.

\subsection{Metacognition Instruction: The Literature versus the ITMR}

This study identified some discrepancy and congruence between the literature's and the ITMR's criteria representing metacognition instruction and in the following, main findings of this study will be discussed regarding these two sets of criteria.

At elementary school level, the ITMR identified that teaching metacognition was mostly represented by planning (task and text evaluation) and evaluating (task performance). Teachers' presentation behaviors (except for task and performance evaluation) were hardly recognized on the ITMR; however, presentation practices such as teachers' modelling, explaining, and explicitly teaching strategic reading are suggested and highly utilized as the standards of teaching metacognition in literature.

On the ITMR, scaffolding was also identified. In this realm, teachers' scaffolding (via cooperative practices) and peers' scaffolding (by metacognitive discussions) mostly focused on planning reading (task or text evaluation) and regulation of strategies. By identifying readingphase and/or components, the ITMR helped clarify literature's vague presentation of collaborative practices and scaffolding.

Moreover, literature theoretically proposes comprehension monitoring practices for metacognition instruction. These might include teachers' helping students with comprehension monitoring, students' discussing meaning making with teacher and/or peers, or students' using rubrics (e.g.Collins, Brown, \& Holum, 1991; Rosenshine \& Meister, 1994). Comprehension monitoring, on the contrary, was the subtlest facet on the ITMR. Approaching the ITMR critically, I have to declare potential influences of educational standards (i.e. Common Core 
State Standards) in the context of this study. These standards already require teachers to present and instruct foundational reading skills; therefore, such practices must be common in classrooms.

The most distinctive criteria of classroom metacognition instruction were set by assessment practices. By assessment practices, all stages of strategic reading were identified on the ITMR. That is, students' doing self-assessment of strategic reading and teachers' having students demonstrate task evaluation, text evaluation, comprehension monitoring, and performance evaluation identified on the ITMR. Indeed, these aspects confirm previous arguments (i.e. Lai, 2011; Ozturk, 2017a) of that metacognition is not assessed regularly and traditionally at schools. Therefore, the ITMR's identifying teachers' assessing and then providing feedback on students' strategic reading may not be a coincidence. Moreover, the ITMR's identifying students' doing self-assessment of strategic reading corresponds to the nature of autonomous metacognitive readers as highlighted in the literature (e.g. Afflerbach \& Cho, 2009; Afflerbach \& Meuwissen, 2005; Veenman et al., 2006).

Lastly, in relation to assessment, students' demonstration of strategic reading organically emerged on the ITMR. For teachers to assess students' strategic reading and for students to reflect on and evaluate strategic reading, students' demonstration of strategic experiences is compulsory. These aspects correspond to the criteria presented in the literature; literature recommends teachers' and students' thinking aloud strategic readings or teachers' evaluating students' reading action plans (e.g. (Baumann, Jones, \& Seifert-Kessell, 1993; McKeown \& Gentilucci, 2007).

\subsection{Metacognition Instruction across Elementary School}

This study found that there were no mean differences in metacognition instruction practices across elementary school grades. By so, the ITMR may be applied across all elementary grades. However, the structure of the ITMR reflecting a subtle presence of teacher's presentation of strategic reading and a distinctive proclivity towards assessment practices proposes that classroom teachers might deliver instruction in certain ways.

As seen on Figure 2, teachers' metacognition instruction practices were dived into two distinct sets. On the top, teachers' dominant instructional practices piled up. This set included mostly presentation practices; modeling, explaining, explicitly teaching, and scaffolding students' strategic reading. Therefore, the current classroom trend might be the reason that the ITMR hardly captured such practices.

The least frequently implemented practices pertained to students' agency with strategic reading. This set of practices included encouraging students' demonstration of independent strategic reading, students' scaffolding each other especially via metacognitive discussions, and having students do self-assessment. While these practices were captured by the ITMR, only few researchers including Fisher, (1998, 2007) and Hartman (2001) highlighted utility of metacognitive discussions or dialogic talks for metacognition instruction. Furthermore, as seen on Figure 2, students might not be given enough opportunities to do self-assessment in mainstream classrooms although students gain confidence, mastery, and independence with strategic reading by self-assessment (Afflerbach \& Meuwissen, 2005).

Finally, teachers' assessment practices could be blending with or supporting presentation practices as can be interpreted from Figure 2. Although assessing students' strategic reading seems to transpose divergently across the grades, it seems that teachers mostly assessed or utilized the insights while presenting strategic reading or working with students. This is because presentation practices (i.e. modeling, explaining, and explicitly teaching strategic reading) were strongly and positively correlated with teachers' assessment practices. 


\subsection{Assessment: A Crucial Element of Metacognition Instruction in Reading Classrooms}

The discrepancy between the classroom metacognition instruction trends identified in this study and the ITMR's items cannot be ignored regarding assessment practices. Considering demanding educational standards, institutional policies, time pressure, curriculum mandates, high-stake tests, and teachers' expertise with metacognition instruction, it may be that assessment practices were hardly practiced in classrooms. However, the ITMR's criteria highlights the discriminatory importance of assessment (teachers' and students' selfassessment) in developing students' metacognition.

Considering the reciprocal relation between assessment and instruction, teachers' assessing students' metacognition may potentially promote students' metacognition. Teachers can inform and regulate instructional practices for students' metacognition only when they assess students' metacognition competence and needs. After assessing, teachers who are informed about students' current proficiencies with metacognition can implement a need-based and goaloriented instruction (Ozturk, 2017a). It is after assessing students' metacognition, teachers can decide whether and how to implement metacognition instruction practices practically to address students' extant needs.

Moreover, students' doing self-assessment is the other indispensable pillar of metacognition instruction in classrooms. The purpose of metacognition instruction is to develop students' vicarious control over thinking and their cognitive enterprises (e.g. Papleontiou-louca, 2003; Zimmerman, 2002). Metacognitive readers do self-assessment continuously to test their decisions, behaviors, and impacts of these on and for successful reading experiences. Selfassessment is, in fact, the collection of metacognitive capability (Afflerbach \& Meuwissen, 2005); therefore, autonomous readers can direct and control their experiences by doing selfassessment.

\section{IMPLICATIONS}

\subsection{Validity Studies}

By the ITMR, this study can initiate a new pathway to study metacognition instruction. First of all, I strongly recommend following a validity-research plan. Messick $(1993,1994)$ proposed six aspects of validity and this study provided sufficient evidence for content, substantive, and structural validity of the ITMR. Regarding the limitations of this study that stem from data collection procedures (i.e. online) and sampling procedures, The ITMR's use might not be applicable in different settings or its interpretation might be misleading in some settings. For this, I propose future studies to examine (1) the generalizability of the ITMR and to re-run exploratory and/or confirmatory factor analyses before conducting inferential studies. Research should also study (2) the external validity of the ITMR by examining its correlation to other measures. It is also important for future research to examine (3) the consequential validity of the ITMR by especially conducting longitudinal studies. Rather than examining metacognition instruction at a time or for short periods of time, research should study such instructions for sufficient periods to identify the instructional patterns, adequately.

\subsection{Educational Implications}

While designing this study, I had an altruistic purpose of transferring metacognition litearture to mainstream classrooms, practically. By so, metacognition's beneficial impacts can be observed there. I anticipate this study satisfies teachers' extant needs of metacognition pedagogies and it becomes a supplementary tool. Teachers can adopt the ITMR as a rubric to inform and self-assess their instruction for metacognition.

Moreover, the ITMR can be used to initiate a change in teachers' professional competence. That is, the ITMR can be used to detect the aspects that teachers need scaffolding or 
improvement. By so, rather than exposing teachers to generic modules of metacognition instruction, needs-based professional development modules at classroom-, school-, or locallevels can be delivered.

\section{Acknowledgements}

This study presents partial findings of the doctoral dissertation entitiled Identifying the Nature of Metacognition Instruction in Reading Classrooms (Ozturk, 2017b). I would like to express my sincere gratitude and deepest appreciation to my professors, colleagues, friends, and participants who made this study possible.

\section{Declaration of Conflicting Interests and Ethics}

The authors declare no conflict of interest. This research study complies with research publishing ethics. The scientific and legal responsibility for manuscripts published in IJATE belongs to the author(s).

\section{ORCID}

Nesrin Ozturk (D) https://orcid.org/0000-0002-7334-8476

\section{REFERENCES}

Afflerbach, P., \& Cho, B.-Y. (2009). Identifying and describing constructively responsive comprehension strategies in new and traditional forms of reading. In S. E. Israel \& G. G. Duffy (Eds.), Handbook of research on reading comprehension (pp. 69-90). New York, NY: Routledge.

Afflerbach, P., \& Meuwissen, K. (2005). Teaching and learning self-assessment strategies in middle school. In S. E. Israel, C. Collins Block, K. L. Bauserman, \& K. Kinnucan-Welsch (Eds.), Metacognition in literacy learning: Theory, assessment, instruction, and professional development (pp. 141-164). Mahwah, NJ: Erlbaum.

Anastasiou, D., \& Griva, E. (2009). Awareness of reading strategy use and reading comprehension among poor and good readers. Elementary Education Online, 8(2), 283297.

Andres, L. (2012). Designing and doing survey research. London, England: SAGE.

Baker, L. (2017). The development of metacognitive knowledge and control of comprehension: Contributors and consequences. In K. Mokhtari (Ed.), Improving reading comprehension through metacognitive reading strategies instruction (pp. 1-31). Lanham, MD: Rowman \& Littlefield.

Bandura, A. (1986). Social foundations of thought and action: A social cognitive theory. Englewood Cliffs, NJ: Prentice-Hall.

Bandura, Albert. (1971). Social learning theory. Morristown, NJ: General Learning.

Bartlett, J. E., Kotrlik, J. W. K. J. W., \& Higgins, C. (2001). Organizational research: Determining appropriate sample size in survey research. Information Technology, Learning, and Performance Journal, 19(1), 43-50.

Baumann, J. F., Jones, L. A., \& Seifert-Kessell, N. (1993). Using enhance comprehensi monitoring The authors think chil ilouds dren' $\mathrm{s}$ ion al program for teaching students think aloud during reading as a means. The Reading Teacher, 47(3), 184-193.

Bolhuis, S., \& Voeten, M. J. . (2001). Toward self-directed learning in secondary schools: What do teachers do? Teaching and Teacher Education, 17(7), 837-855.

Book, C., Duffy, G. G., Roehler, L. R., Meloth, M. S., \& Vavrus, L. G. (1985). A study of the relationship between teacher explanation and student metacognitive awareness during reading instruction. Communication Education, 34, 29-36.

Boulware-Gooden, R., Carreker, S., Thornhill, A., \& Joshi, R. M. (2007). Instruction of metacognitive strategies enhances reading comprehension and vocabulary achievement 
of third-grade students. The Reading Teacher, 61(1), 70-77.

Bradburn, N. M., Sudman, S., \& Wansink, B. (2004). Asking questions: The definitve guide to questionnaire design for market research, political polls, and social and health questionnaires (Revised). San Francisco, CA: Jossey-Bass.

Bransford, J., Brown, A. L., \& Cocking, R. R. (2000). How people learn: Brain, mind, experience, and school (Expanded). Washington DC: National Academy.

Carroll, M. (2008). Metacognition in the classroom. In J. Dunlosky \& R. A. Bjork (Eds.), Handbook of metamemory and memory (pp. 411-427). New York: Psychology Press.

Collins, A., Brown, J. S., \& Holum, A. (1991). Cognitive apprenticeship: Making thinking visible. American Educator, 15(3), 6-11.

Cross, D. R., \& Paris, S. G. (1988). Developmental and instructional analyses of children's metacognition and reading comprehension. Journal of Educational Psychology, 80(2), 131-142. https://doi.org/10.1037/0022-0663.80.2.131

Curwen, M. S., Miller, R. G., White-Smith, K. A., \& Calfee, R. C. (2010). Increasing teachers' metacognition develops students' higher learning during content area literacy instruction: Findings from the read-write cycle project. Issues in Teacher Education, 19(2), 127-151.

de Winter, J. C. F., Dodou, D., \& Wieringa, P. A. (2009). Exploratory factor analysis with small sample sizes. Multivariate Behavioral Research, 44(November), 147-181.

DeVellis, R. F. (2012). Scale Development: Theory and applications (3rd ed.). Thousand Oaks, CA: SAGE.

Doğanay Bilgi, A., \& Özmen, E. R. (2014). The impact of modified multi-component cognitive strategy instruction in the acquisition of metacognitive strategy knowledge in the text comprehension process of students with mental retardation. Educational Sciences: Theory \& Practice, 14(2), 707-714.

Duffy, G. G. (1993). Rethinking strategy instruction: Four teachers' development and low achievers' understandings. Elementary School Journal, 93(3), 231.

Duffy, G. G. (2002). The case for direct explanation of strategies. In C. C. Block \& M. Pressley (Eds.), Comprehension instruction: Research-based best practices (pp. 28-41). New York: Guilford.

Fisher, D., \& Frey, N. (2013). Better learning through structured teaching: A framework for the gradual release of responsibility (2nd ed.). Alexandria, VA: ASCD.

Fisher, Robert. (1998). Thinking about thinking: Developing metacognition in children. Early Child Development and Care, 141(1), 1-15.

Fisher, Robert. (2007). Dialogic teaching: Developing thinking and metacognition through philosophical discussion. Early Child Development and Care, 177(6-7), 615-631.

Fisher, Ros. (2002). Shared thinking: Metacognitive modelling in the literacy hour. Reading, $36(2), 63-67$.

Flavell, J. H. (1979). Metacognition and cognitive monitoring: A new area of cognitivedevelopmental inquiry. American Psychologist, 34(10), 906-911.

Fowler, F. J. (2009). Survey research methods (4th ed.). Thousand Oaks, CA: Sage.

Fowler, F. J. (1995). Improving survey questions: Design and evaluation. Thousand Oaks, CA: SAGE.

Garner, R. (1987). Metacognition and reading comprehension. Norwood, NJ: Ablex.

Goldring, R., Gray, L., \& Bitterman, A. (2013). Characteristics of Public and Private Elementary and Secondary School Teachers in the United States: Results From the 201112 Schools and Staffing Survey (NCES 2013-2014). Washington DC: NCES, IES, U.S. Department of Education. Retrieved from https://nces.ed.gov/pubs2013/2013314.pdf

Gourgey, A. F. (1998). Metacognition in basic skills instruction. Instructional Science, 26, 8196.

Gourgey, A. F. (2001). Metacognition in basic skills instruction. In H. J. Hartman (Ed.), 
Metacognition in learning and instruction: Theory, research, and practice (pp. 17-32). Boston: Kluwer.

Guadagnoli, E., \& Velicer, W. F. (1988). Relation to sample size to the stability of component patterns. Psychological Bulletin, 103(2), 265-275.

Hartman, H. J. (2001). Developing students' meatcognitive knowledge and skills. In H. J. Hartman (Ed.), Metacognition in learning and instruction: Theory, research, and practice (pp. 33-68). Boston: Kluwer.

Hinkin, T. R. (1995). A review of scale development practices in the study of organizations. Journal of Management, 21(5), 967-988.

Kerndl \& Aberšek, M. K. (2012). Teachers' competence for developing reader's reception metacognition. Problems of Education in the 21st Century, 46(1979), 52-61.

Kurtz, B. E., Schneider, W., Carr, M., Borkowski, J. G., \& Rellinger, E. (1990). Strategy instruction and attributional beliefs in West Germany and the United States: Do teachers foster metacognitive development? Contemporary Educational Psychology, 15(3), 268283. https://doi.org/http://dx.doi.org/10.1016/0361-476X(90)90024-U

Lai, E. R. (2011). Metacognition: A Literature review (Research report). New York, NY:Pearson. Retrieved from http://www.datec.org.uk/CHAT/chatmeta1.htm

McKeown, R. G., \& Gentilucci, J. L. (2007). Think-aloud strategy: Metacognitive development and monitoring comprehension in the middle school second-language classroom. Journal of Adolescent \& Adult Literacy, 51(2), 136-147.

Messick, S. (1993). Foundations of validity: Meaning and consequences in psychological assessment (RR-93-51). Princeton, New Jersey: Educational Testing Service.

Messick, S. (1994). Validity of psychological assessment: Validation of inferences from persons' responses and performances as scientific inquiry into score meaning (RR-9445). Princeton, New Jersey: Educational Testing Service.

Muñiz-Swicegood, M. (1994). The effects of metacognitive reading strategy training on the reading performance and student reading analysis strategies of third grade bilingual students. Bilingual Research Journal, 18, 83-97. https://doi.org/10.1080/15235882.1994 .10162659

Myers, M., \& Paris, S. G. (1978). Children's metacognitive knowledge about reading. Journal of Educational Psychology, 70(5), 680-690.

Netemeyer, R. G., Bearde, W. O., \& Sharma, S. (2003). Scaling procedures: Issues and applications. Thousand Oaks, CA: SAGE.

Nunnally, J. C. (1978). Psychometric theory (2nd ed.). New York: McGraw-Hill.

Ozturk, N. (2015). A short review of research on metacognition training. Journal of Educational and Instructional Studies in the World, 5(3), 50-62.

Ozturk, N. (2016). An analysis of pre-service elementary teachers' understanding of metacognition and pedagogies of metacognition. Journal of Teacher Education and Educators, 5(1), 47-68.

Ozturk, N. (2017a). Assessing metacognition: Theory and practices. International Journal of Assessment Tools in Education, 4(2), 134-148.

Ozturk, N. (2017b). Identifying the nature of metacognition instruction in reading classrooms (Unpublished doctoral dissertation). University of Maryland, College Park, Maryland.

Papleontiou-louca, E. (2003). The concept and instruction of metacognition. Teacher Development, 7(1), 9-30. https://doi.org/10.1080/13664530300200184

Pearson, P. D., \& Gallagher, G. (1983). The gradual release of responsibility model of instruction. Contemporary Educational Psychology, 8, 112-123.

Perry, N. E., Hutchinson, L., \& Thauberger, C. (2008). Talking about teaching self-regulated learning: Scaffolding student teachers' development and use of practices that promote self-regulated learning. International Journal of Educational Research, 47, 97-108. 
Pintrich, P. R., Wolters, C. A., \& Baxter, G. P. (2000). Assessing metacognition and selfregulated learning. In Gregory Schraw \& J. C. Impara (Eds.), Assessing metacognition and self-regulated learning (pp. 43-97). Lincoln, NE: Buros Institute of Mental Measurements.

Pintrich, Paul R. (2002). The role of metacognitive knowledge in learning, teaching, and assessing. Theory Into Practice, 41(4), 219-225.

Rahman, T., Fox, M. A., Ikoma, S., \& Gray, L. (2017). Certification Status and Experience of U.S. Public School Teachers: Variations Across Student Subgroups (NCES 2017-056). Washington, DC: U.S. Government Printing Office. Retrieved from https://nces.ed.gov/pubs2017/2017056.pdf

Rosenshine, B., \& Meister, C. (1994). Reciprocal teaching: A review of the research. Review of Educational Research, 64(4), 479-530.

Schraw, G. (2001). Promoting general metacognitive awareness. In H. J. Hartman (Ed.), Metacognition in learning and instruction: Theory, research, and practice (pp. 3-16). Boston, MA: Kluwer.

Schwab, D. P. (1980). Construct validty in organization behavior. In B. M. Staw \& L. L. Cummings (Eds.), Research in organizational behavior (Vol 2, pp. 3-43). Greenwich: JAI.

Sue, V. M., \& Ritter, L. A. (2012). Conducting online survey (2nd ed.). Thousand Oaks: SAGE.

Thomas, K. F., \& Barksdale-ladd, M. A. (2000). Metacognitive processes: Teaching strategies in literacy education courses. Reading Psychology, 21, 67-84.

Tishman, S., \& Perkins, D. (1997). The language of thinking. The Phi Delta Kappan, 78(5), 368-374.

Van Keer, H., \& Vanderlinde, R. (2010). The impact of cross-age peer tutoring on third and sixth graders' reading strategy awareness, reading strategy use, and reading comprehension. Middle Grades Research Journal, 5(1), 33-45.

Veenman, M. V. J. (2016). Metacognition. In P. Afflerbach (Ed.), Handbook of individual differences in reading (pp. 26-40). Routledge.

Veenman, M. V. J., Van Hout-Wolters, B. H. A. M., \& Afflerbach, P. (2006). Metacognition and learning: Conceptual and methodological considerations. Metacognition and Learning, 1(1), 3-14. https://doi.org/10.1007/s11409-006-6893-0

Vygotsky, L. S. (1978). Mind in society: The development of higher psychological processes. Cambridge, MA: Harvard University Press.

Wilson, N. S., \& Bai, H. (2010). The relationships and impact of teachers' metacognitive knowledge and pedagogical understandings of metacognition. Metacognition and Learning, 5(3), 269-288. https://doi.org/10.1007/s11409-010-9062-4

Zimmerman, B. J. (2000). Attaining self-regulation: A social cognitive perspective. In M. Boekaerts, P. R. Pintrich, \& M. Zeidner (Eds.), Handbook of self-regulation (pp. 13-39). San Diego, CA: Academic.

Zimmerman, B. J. (2002). Becoming a self-regulated learner: An Overview. Theory Into Practice, 41(2), 64-70. https://doi.org/10.1207/s15430421tip4102

Zohar, A. (1999). Teachers' metacognitive knowledge and the instruction of higher order thinking. Teaching and Teacher Education, 15(4), 413-429. 